contrast, values for $r$ on Storglaciären are as high as $2.5 \times 10^{-2} \mathrm{yr}^{-1}$ owing to greater ice velocities and variation in ice velocity. Since the response time of a glacier is proportional to $1 / \mathrm{r}$, the lower strain rates found on Rabots glaciär probably account for its more sluggish retreat.

A simple, non-diffusive, kinematic wave model is used to analyze the response of the glaciers to a step-like perturbation in mass balance. This model predicts that the response time of Storglaciären is on the order of 30 years and that a new steady-state profile would be attained in about 50 years. The predicted response time of Rabots glaciär is about 75 years, its new steady-state profile being reached after more than 100 years.

More accurate analyses of each glacier's response to climatic change use a time-dependent numerical model which includes the effects of diffusion. The climatic forcing in these modelling efforts is represented by the changes in mass balance resulting from changes in the equilibrium line altitude (ELA). ELAs can be correlated to regional meteorological variables which in turn are used to create a "synthetic" record of ELA variations where necessary. Therefore climatic oscillations since the turn of the century can be simulated by the appropriate changes in ELA. Using synchronous variations of ELAs and their 1916 profiles as datum states, the modeled behavior of Rabots glaciär and Storglaciären shows that: (a) the rates of ice retreat for each glacier are in reasonable agreement with those observed; and (b) Rabots glaciär took slightly longer than Storglaciären to react to the slight warming that occurred shortly after their 1916 advance.

\title{
GLACIER LENGTH VARIATIONS AND CLIMATE CHANGE: COMPARATIVE GLACIER DYNAMICS SINCE 1850 IN THE PACIFIC NORTHWEST, U.S.A.
}

\section{(Abstract)}

by

\author{
Melinda M. Brugman
}

(Department of Geology, Western Washington University, Bellingham, WA 98225, U.S.A.)

One possible cause of glacier terminus variation is climate change. The problem with proving or disproving this hypothesis is that the precise relationship between climate change and glacier flow response is still incompletely understood. In this paper, I examine the relationship between recent glacier terminus fluctuations and climate variations documented since the middle 1800 s in the Pacific northwest region of the United States.

Six glaciers located in Washington and one in Oregon are compared in terms of terminus position record, local climate data (temperature, precipitation, snowfall and runoff records) and also in terms of what is known about the flow dynamics of each glacier. A simple model is presented to simulate the observed response behavior of each glacier. The variables modeled here include surface and bed slope, ice thickness, glacier length, sliding and deformation mechanics, seasonality of glacier flow velocity, traveling wave dynamics, snow accumulation and ablation patterns, runoff, regional temperature and precipitation. Mainly, information obtained at Blue, South Cascade and Nisqually glaciers are compared to results obtained by the author at Shoestring Glacier on Mount St. Helens. Others studied include Forsythe, Elliot, Coleman glaciers. The effects of local volcanic eruptions are separated from those attributed to climate change.

Local climate records show that times of cool-wet weather alternate with warm-dry weather on a time scale of 15 to 20 years. In general, no definable long-term trend of annual average temperature and precipitation is apparent in the climate records (starting in the mid-1800s), except for a suggestion of slightly increased annual precipitation in the northern part of Washington since about 1930. The availability and reliability of different types of climate data is discussed in the paper.

At Shoestring Glacier, the observed rapid response to environmental changes (both climate and volcanic) is shown to be directly related to readily-described mechanics of glacier sliding, internal deformation and englacial thrusting along discrete shear zones. For other glaciers, a combination of a rapid sliding response and a slow long-term deformation and sliding response is apparent, and related to that of the Shoestring Glacier.

Where stagnant ice exists at or near a glacier terminus, the response behavior may be further complicated. The stagnant ice is of ten overthrust and buried by reactivated ice moving down from higher elevations. In other situations, stagnant terminus ice is accreted to the front of the reactivated portion of a glacier and shoved downhill. This behavior is seen at Shoestring and Nisqually glaciers.

Traveling waves (resembling kinematic waves) are apparent at three of the glaciers studied and probably occur to some degree at all the glaciers. Understanding of the details of glacier flow dynamics and existing terminus conditions helped to formulate a simple model that I use to simulate terminus fluctuation records of all seven glaciers.

Records of terminus position studies indicate that three distinct trends exist for this region. The first is a long-term trend of progressive retreat throughout historic times (meaning locally since the early 1800s). The second trend is the dramatic decrease in the rate of retreat and (perhaps temporary) minor readvance of some glaciers (Blue, Nisqually, Forsythe, Coleman, Shoestring glaciers) since 1950. The third trend is the short-term oscillation of glacier terminus positions on a cycle of 15 to 20 years that has occurred since 1950.

Except for a slight hint of increased precipitation since 1950 , the long-term variation in glacier terminus positions cannot be explained by local climate records. This may be attributed to the shortness of the available climate records, and the large variance of annual temperature and precipitation data.

Conversely, the high frequency glacier terminus variations (on the order of 10 to 20 years) are well correlated with local temperature and precipitation fluctuations. For example, Nisqually and Shoestring glaciers advanced when the climate pattern became cool-wet and retreated when the climate changed to warm-dry. Very short lag times are implied by the data for several glaciers, and these are discussed in the paper.

Results indicate that certain local glaciers are very sensitive to short-term climate variations on the order of one to ten years. Large glaciers and glaciers flowing slowly down shallow slopes respond more sluggishly to short-term climate changes, as might be expected. Glaciers with the greatest degree of seasonality in their flow behavior, such as Nisqually and Shoestring glaciers, responded most rapidly. Using this information derived from recent glacier and climate records we may be able to better predict future trends of snow accumulation patterns and climate change. 